\title{
Formas del discurso científico en el Renacimiento: tratados y diálogos ${ }^{1}$
}

\section{Consolación Baranda Leturio}

Universidad Complutense

cbarandal@filol.ucm.es

Fecha de recepción: 08/01/2011, Fecha de publicación: 01/03/2011

<URL: http://www.studiaaurea.com/articulo.php?id=161 >

\section{Resumen}

La renovación de los géneros de literatura científica renacentista ha sido poco estudiada, aunque es un aspecto clave de la transmisión de conocimientos. Más allá de las intenciones académicas, divulgativas o polémicas del autor, la adopción de una forma discursiva concreta tratado, diálogo, libros de preguntas, misceláneas, ensayo, etc.- implica ya una perspectiva de interpretación de la realidad. Este trabajo se ocupa de los únicos textos del siglo XVI integrados por un tratado y un diálogo, concebidos ambos de manera conjunta y complementaria; en él se analizan, específicamente, las virtualidades que se percibían en el diálogo literario como vehículo de la literatura científica. Concluye que para la ciencia renacentista la elección entre ambos géneros no está necesariamente relacionada con los propósitos de mayor o menor divulgación, como suele afirmarse, sino con razones a veces muy complejas que es preciso estudiar en cada caso

\section{Palabras clave}

Renacimiento, literatura científica, tratados, diálogos literarios, Pedro Ciruelo, Montaña de Monserrate, Pérez de Moya

\begin{abstract}
Discursive forms in Renaissance scientific literature: treatise and dialogue

Up until now, there have been few studies dedicated to the renewal of genres in Renaissance scientific literature, despite the fact that this is a key factor of knowledge dissemination. Beyond the author's aims - academic, informative, or controversial-, the adoption of a specific discursive form implies a given perspective in the interpretation of reality. This article deals with the three available sixteenth-century Spanish works
\end{abstract}

1. Este trabajo se realiza en el marco del proyecto HUM2006-07936 del Ministerio de Educación y Ciencia. 
consisting of a treatise and a dialogue designed together as complementary units, and it analyzes the perceived potential of literary dialogue as a vehicle for scientific literature. The conclusion is that Renaissance science does not necessarily choose from these two genres due to issues of knowledge dissemination, as is usually claimed; such a decision may be based on very complex reasons which must be considered in every case.

Key words

Renaissance, scientific literature, treatises, literary dialogues, Pedro Ciruelo, Montaña de Monserrate, Pérez de Moya.

\section{Algunas consideraciones previas sobre la literatura científica en el Renacimiento ${ }^{2}$}

Las obras y géneros científico-técnicos tienen — como todo discurso- unas características peculiares según el momento histórico en que se escriben; en general suele afirmarse que estas obras se distinguen de otro tipo de textos por la mayor carga referencial, la necesidad de objetividad, la univocidad léxica y una cierta claridad discursiva, pero los mecanismos para lograr este imposible ideal de objetividad son distintos antes y después de la revolución científica del siglo XVII.

En el Renacimiento todavía no se han forjado léxicos especializados en las lenguas vernáculas, y aún no existen los lenguajes formales ni las clasificaciones taxonómicas que ahora resultan un elemento primordial de la comunicación científica; por ello — aunque pueda resultar paradójico desde la perspectiva actual - las técnicas de reformulación lingüística, la sinonimia, las redundancias, la expresividad del lenguaje, las analogías y las metáforas son una necesidad de todo discurso científico renacentista.

En la elección de género inciden múltiples factores. Habría que tener presente que en algunas materias los referentes clásicos son de tal peso que resulta difícil modificar la forma en que los conocimientos habían sido legados por la tradición, como indica Ma Pilar Cuartero (1993). También sería necesario analizar: si existe una preferencia por géneros concretos en los momentos de estabilidad o de cambio del paradigma científico; en qué medida se relaciona la

2. Rehúyo deliberadamente los calificativos de «didáctico» $\mathrm{y}$ "pedagógico», frecuentemente utilizados como rasgo peculiar de los diálogos, porque no sirven para marcar diferencias entre ambos géneros, pues del tratado se podría decir lo mismo: es el género didáctico por excelencia. 
renovación de los géneros de la literatura científica con la aparición y difusión de nuevos modelos literarios; $y$, por supuesto, la influencia de la censura.

Rasgo común a la literatura científica del Renacimiento es que opera con una fuerte conciencia de la estratificación del saber. En función del nivel social y cultural de los receptores a quienes quieran dirigirse, los autores pueden elegir entre dos lenguas - latín, vernacular- $y$, además, entre varios géneros: tratado, diálogo, libros de problemas, misceláneas, etc. En la misma especialidad científica encontramos tratados académicos escritos en latín, dirigidos a lectores muy cualificados, junto a otros escritos en lengua vulgar que, con idéntico rigor muchas veces, pretenden atraer a grupos más amplios de lectores. A su vez, en los textos científicos en lengua vulgar, cada uno de los géneros es susceptible de ser dirigido a diferentes ámbitos de especialización. Así, entre un tratado de medicina vernacular pensado para círculos profesionales y un «tesoro de pobres» media un abismo en la cualificación de los receptores; el escritor debe adaptarse a ellos y utilizar diferentes recursos discursivos en cada caso. ${ }^{3}$ Dentro de cada uno de los campos de la ciencia existe una gran diversidad de niveles de especialización; los discursos científicos sobre de la misma materia no son homogéneos. ${ }^{4}$

Por esta razón, los autores de textos científicos renacentistas muestran una profunda tendencia a justificar el propio discurso; su conciencia y preocupación metalingüística es comparable a la de los escritores de obras incluidas en el canon literario. Los prólogos — a veces, incluso los títulos-, junto a la justificación sobre el uso de la lengua vulgar, incluyen siempre referencias explícitas al tipo de lectores a los cuales está destinado el libro. ${ }^{5}$ A medida que se amplía el ámbito de la recepción, es necesario multiplicar las técnicas de divulgación ligadas a procedimientos de reformulación lingüística con el fin de facilitar la lectura comprensiva de lectores no especialistas; tales técnicas están presentes en cada uno de los géneros. Un ejemplo conocido y paradigmático para observar la importancia de estos procedimientos en un tratado científico es la traducción del Dioscórides realizada por el doctor Laguna, entre otros muchos otros casos. ${ }^{6}$ Así, por ejemplo, Arfe Villafañe escribió De varia commensuración para la esculptura y architectura (1585), ${ }^{7}$ destinado a plateros y escultores, gentes sin formación académica. Es un tratado en el que dos de los libros están dedicados a la geometría y a la anatomía,

3. En el caso concreto de la medicina, es muy ilustrativo el estudio de Bertha Gutiérrez Rodilla (2005) con información cuantitativa acerca de la proliferación de tratados destinados a sanadores y empíricos especializados (algebristas, sacamuelas, parteras, hernistas, etc.)

4. Es peculiaridad escasamente señalada; a este respecto es espléndido el trabajo de $\mathrm{M}^{\mathrm{a}}$ Luisa Altieri-Biagi (1998, 26 y 27)

5. Altieri Biagi (1998, 22). Es casi imposible encontrar un tratado científico en lengua vulgar en el que no se justifique la elección de la lengua y no se aluda al tipo de lectores a quienes va dirigida la obra, vid. Domingo Ynduráin (1982), C. Baranda (1992) y Ma Jesús Mancho (2001).

6. Vid. C. Baranda (1993) y A. Vian Herrero (2001).

7. Introducción de Antonio Bonet Correa (1974). 
pero, ante la necesidad de acomodar el texto a esos receptores concretos, el nivel de la exposición difiere mucho de otros destinados a especialistas en tales materias (matemáticos o médicos). Utiliza además recursos adicionales diferentes para permitir la posibilidad de lectores con varios niveles de cualificación: destacan a este respecto la abundancia de ilustraciones, que casi pueden sustituir la lectura comprensiva del texto, y el empleo del verso: los contenidos relevantes de cada apartado se resumen en unas octavas reales a fin de facilitar la memorización de las reglas. Es un tratado especializado pero también divulgativo, que permite diferentes niveles de lectura en función del grado de cualificación de los lectores, incluido el de los casi iletrados. ${ }^{8}$

En la práctica, en los textos, se observa la existencia de propósitos divulgativos fuertes tanto en muchos tratados en lengua vernácula como en muchos diálogos, $y$, al mismo tiempo, en ambos géneros existen ejemplos de un alto grado de especialización.

Mientras en el tratado el nivel de divulgación depende de los procedimientos de reformulación lingüística empleados (junto a ilustraciones, recursos mnemotécnicos, etc., como hemos visto), en el diálogo intervienen además elementos ficcionales tales como la caracterización de los personajes y su respectiva cualificación en la materia desarrollada; el proceso argumentativo será más especializado cuanto mayor sea el grado de cualificación de los interlocutores y el equilibrio entre ellos; por el contrario, el diálogo será tanto más divulgativo cuanto mayor sea el desnivel en los conocimientos entre los personajes que intervienen, a medida que sus funciones se polarizan esquemáticamente en las de maestro y discípulo.

Es cierto que en algunos diálogos se vincula expresamente la elección del género con el propósito de aumentar la difusión y llegar a un mayor número de lectores, pero tales afirmaciones son inevitables también en los prólogos de los tratados escritos en lengua romance (vg.el Sumario de Medicina de Villalobos (1498), la Suma de tratos y contratos de Tomás de Mercado (1571), la Agricultura de Herrera (1513), la traducción del Dioscórides de Laguna (1555), etc.). En definitiva, el propósito divulgativo no parece ser la marca específica que sirva para explicar la preferencia de un autor por uno u otro género, pues ambos son capaces de altos niveles de especialización y de las mayores posibilidades de divulgación. Otra cosa es la frecuencia de un uso u otro en cada uno de ellos.

Desde el punto de vista de la enunciación, la diferencia más obvia entre tratados y diálogos de materia científico-técnica remite al uso de la tercera persona en los primeros y a la presencia de discursos directos entre los interlocutores ficticios

8. La posibilidad de múltiples lecturas y niveles de especialización es común a otros tratados, como el mismo Dioscórides de Laguna o la Aritmética de Pérez de Moya (1998); en este último confraternizan un libro dedicado a la «regla de la cosa» (álgebra) con otro en el que se dan reglas para cambiar monedas y contar con los dedos; obviamente están pensados para diferentes destinatarios, puesto que el orden no siempre se ajusta a la progresiva dificultad en la materia. 
o ficcionalizados en los segundos. En los tratados, con el empleo de la tercera persona se pretendería asegurar la asepsia, la impersonalidad de los asertos emitidos, en definitiva dotar de objetividad al discurso; en cambio, en los diálogos las afirmaciones de cada interlocutor están mediatizadas por su propia voz, por lo cual sus discursos se acercarían al ámbito de la opinión, de lo opinable, lo que parece recortar el alcance de su objetividad.

Pero la asepsia científica no existe; por definición, no hay texto sin contexto. Los tratados pertenecen a un género convencional - tan convencional como cualquier otro- con una codificación relativamente estable desde el mundo griego. Los científicos necesitan de la escritura para validar sus aportaciones, lo hacen siempre sometidos a unas normas formales y en un contexto de competencia y de polémica con otras obras y otras aportaciones; ${ }^{9}$ incluso en las compilaciones o estados de la cuestión renacentistas sobre distintas materias es imprescindible la toma de partido. Las palabras de Gabriel Alonso de Herrera se pueden aplicar al cometido de cualquier autor de un tratado científico en el Renacimiento: "puedo decir con verdad ser yo el primero que aya procurado poner en nuestro castellano las reglas y arte dello [de agricultura] ... lo qual quánto sea trabajoso concordando a las veces discordes autores, desechar, escoger y reprovar algunas costumbres y usos antiguos y modernos, Vuestra Señoría Ilustríssima lo vee». ${ }^{10}$

Esta tarea de seleccionar, desechar y reprobar es indispensable en todo tipo de tratados, en los que la "tercera persona" toma partido ya desde la fase previa a la elaboración del texto y critica a antiguos y modernos en soterrados enfrentamientos profesionales, por lo cual no es de extrañar en ellos la frecuente presencia explícita o implícita del yo autorial. ${ }^{11}$ No falta tampoco la exhortación directa del autor a los lectores; en ocasiones los textos llegan a interpelar a sus receptores en su afán de modificar hábitos, costumbres o desterrar lo que consideran falsedades, en algún caso, incluso se dirigen a ellos para comentar dudas. ${ }^{12}$

La dimensión polémica, de divergencia y pluralidad de puntos de vista, no es exclusiva de los diálogos, donde aparece de forma aparentemente natural — puesto

9. En la actualidad ya no es de recibo aplicar mecánicamente el esquema de Jakobson a las diferencias entre los discursos científicos (referenciales) y literarios (connotativos), ni las tesis de Leonard Bloomfield; vid. David Locke (1992). En los tratados científicos no es nada extraña la implicación personal del autor en la materia, lo cual tińe los textos de expresividad (basten como ejemplo Alonso de Herrera, Andrés Laguna o incluso Darwin), mediante comparaciones, metáforas $\mathrm{u}$ otros procedimientos como el uso de diminutivos.

10. Ed. J. U. Martínez Carreras $(1950,6)$.

11. Para ejemplos del Renacimiento vernacu- lar, Baranda (1992); para el uso de la primera persona también en publicaciones científicas contemporáneas, el capítulo titulado irónicamente «Escritura sin expresión» en Locke (1992, 87-121).

12. Como ejemplo extremo, sólo uno, del mismo Alonso de Herrera; a propósito de una hierba que Paladio llama culex dice «...yo no sé ni he podido hallar ni entender qué yerba sea y quien supiere qué yerba es y cómo se llama, yo le ruego y le pido de gracia que la declare aquí, y asimismo ponga su nombre, que en ello hará a Dios servicio, a mí merced, y a muchos buena obra» $(1950,233)$. 
que las opiniones enfrentadas están encarnadas en distintos interlocutores-, también está presente de manera encubierta o manifiesta en los tratados, y no es, por tanto, una marca que permita establecer diferencias en ambas formas de discurso científico.

Como resultado de esta diferencia en la enunciación entre el tratado y el diálogo se produce una curiosa paradoja que sí puede ser relevante para explicar por qué en algunos casos un autor se decanta por uno y otro género. Aunque el autor de un tratado se oculte bajo la convencional impersonalidad de la tercera persona - o la modestia de la primera persona del plural, que en este caso englobaría a una parte de la comunidad científica - nadie dudaría en atribuirle a él específicamente las afirmaciones consignadas en su obra: las convenciones del género - como esa falsa e imposible impersonalidad- funcionan en una doble dirección, para el emisor y para los receptores que identifican esa tercera persona con la voz del autor.

En cambio, en el diálogo los interlocutores no son nunca personas reales, sino entes de ficción — aunque se trate de personajes históricos - que exponen sus ideas en primera persona en polémica o asenso con las de los demás participantes en el coloquio. De esta forma los personajes actúan como intermediarios entre el escritor y las ideas expuestas, por ello el diálogo — a diferencia del tratado- posibilita una mayor distancia entre el autor y las tesis defendidas en él. Este hecho abre posibilidades al disimulo de la voz autorial, a la ocultación, la ambigüedad o a la falta de compromiso que no pasaron desapercibidas en el Renacimiento. Venegas advertía de los peligros encerrados en el diálogo porque «debaxo desta forma de escrebir se suele esconder la zizańa que el diablo quiere sembrar entre el trigo, porque debaxo de agena persona osa escrebir el escriptor amador de singularidad lo que sin su peligro no osaría escrebir en su propia persona»; o como dice Francisco Mexía, «esta manera de plática [...] tira la piedra y esconde la mano». ${ }^{13}$ Los resquicios que ofrece el diálogo para esquivar compromisos con las opiniones vertidas fueron utilizados en momentos históricos en que la defensa de determinadas posiciones científicas o filosóficas no era posible, o era poco aconsejable y segura. La muestra más conocida del período es la obra de Galileo: cuando escribe su Dialogo sopra i due massimi sistemi del mondo (1632) es obvio que no elige el género por simple afán divulgativo, sino por razones mucho más complejas y sutiles que incluyen la ocultación de la voz autorial, aunque la estrategia en su caso no llegó a tener el éxito deseado.

El contraste más obvio entre ambos géneros reside en su estructura, en el carácter sistemático del tratado frente al aparente desorden del diálogo, que se suele

13. Baranda (en prensa) y Francisco Mexía, Diálogo del soldado (Valencia, Juan Navarro, 1555): «Esta manera de plática cierra a dos por tres con su adversario, y dando toque franco muchas veces se retira con tan lindo denuedo que paresce con su disimulación no haver hecho de las suyas ... tira la piedra y esconde la mano»; citado por Domingo Ynduráin (2006, 342). 
presentar como mimesis de una conversación real. ${ }^{14}$ En los tratados la transmisión progresiva del conocimiento se apoya en un orden estricto que exhibe el trabajo de planificación previa a la redacción del texto mediante divisiones y subdivisiones en libros, capítulos y artículos; en el Renacimiento es habitual la inclusión de índices o tablas para facilitar la consulta del contenido. El deseo de ofrecer rigor científico y el afán totalizador, la aspiración de abarcar todo lo conocido sobre la materia, encuentran su reflejo formal en la rigidez de la disposición, en la formalización ordenada, estricta y sistemática que imponen las convenciones del género.

En el diálogo científico, en cambio, la transmisión de conocimientos se presenta «in fieri», va asociada al proceso de argumentación; mientras el tratado ofrece unos saberes depurados, cerrados, en el diálogo de materia científica asistimos y participamos del "proceso de producción colectiva del conocimiento». ${ }^{15} \mathrm{El}$ desarrollo argumentativo del diálogo se debate entre la necesidad de imitar el cierto desorden de una conversación - con saltos de un asunto a otro, digresiones, bromas, etc. - y la obligatoriedad de progresar hacia un consenso final en torno a la materia científica que desarrolla; el orden puede ser sobreimpuesto en algunos casos mediante reglas previas más o menos estrictas (vg. turnos de palabra) y otros procedimientos — como veremos más adelante—, pero aun sin tales apoyos debe avanzar hacia un desenlace mediante acuerdos parciales y respetar a la vez el decoro en el diseño de personajes y el contexto ficcional.

Como se decía antes, la oposición entre ambas modalidades de discurso científico no radica realmente en la polifonía del diálogo frente al monologismo del tratado, pues en ambos, con distintos medios, los conocimientos se presentan en competencia con otros. El tratado ofrece unos resultados desde la perspectiva del autor acerca del estado de la materia científica, mientras que el diálogo quiere dar la impresión de que asistimos a la búsqueda de esos resultados, porque los interlocutores deben avanzar modificando o reforzando el estado de cosas anterior y ello exige implicación mucho más activa por parte de los receptores. A este respecto, la diferencia fundamental no está en la presencia de disenso — común a ambos géneros - sino en que para que haya diálogo es imprescindible el acuerdo; sólo se puede progresar si junto a la confrontación de ideas se produce una cooperación entre los distintos interlocutores con puntos de vista encontrados o disímiles para llegar a acuerdos parciales y al consenso final. El resultado es la mayor participación del lector en el proceso de conocimiento y la superior eficacia en la transmisión.

A continuación se analizan — aunque sea someramente- las funciones del diálogo en tres textos que reúnen la peculiaridad de ofrecer conjuntamente un tratado y un diálogo sobre la misma materia. Uno de ellos está escrito en latín y los otros dos en lengua vulgar: el Disputatorius dialogus de Pedro Ciruelo publicado junto con el Uberrimum sphere mundi comentum (Paris, 1498), el Coloquio [..] de

14. Mimesis conversacional es expresión acuńada por Ana Vian Herrero (1988) que goza de total asenso.

15. Vid. Vian Herrero (2001, 167 y passim). 
la genaración, nascimiento y muerte del hombre que ocupa la mitad del Libro de la anothomía del hombre de Bernardino Montaña de Monserrate (1551) y el Diálogo de Aritmética de Pérez de Moya, que se publicó con la Artimética práctica y especulativa $\left(1554,1559,1562\right.$, etc.). ${ }^{16}$ El estudio de las funciones que desempeñan los diálogos en estos tres textos permitirá matizar algunos rasgos de las relaciones y diferencias entre el tratado y el diálogo y las virtualidades que los escritores percibían en ambos géneros, en dos formas de comunicación científica por lo general alternativas, que estos libros, en cambio, presentan como complementarias.

\section{Disputatorius dialogus.}

En 1498 se publicó en Paris la obra de Ciruelo integrada por las siguientes partes: un largo prólogo en el que se justifica la dignidad de la astronomía, ${ }^{17}$ los comentarios a la Esfera de Sacrobosco —en los que inserta las famosas 14 Cuestiones sobre la Esfera de Pedro de Ailly- y el Disputatorius dialogus. ${ }^{18}$ Nos encontramos con un repertorio casi completo de géneros especializados en comunicación científica académica: tratado — de Sacrobosco-, comentario — de Pedro Ciruelo—, quaestiones — de Pedro de Ailly_ y, en un lugar privilegiado, como cierre del volumen, un diálogo. El Disputatorius dialogus se desarrolla en Paris entre dos personajes reales vinculados a la Universidad: el burguense o burgalés Gonzalo Gil, y el darocense Pedro Ciruelo, autor de la obra (dos de los introductores del nominalismo en las universidades de Alcalá y Salamanca). Como indica el título se trata de un diálogo polémico en el que dos amigos y colegas discuten — con posturas enfrentadas - a propósito del Commentum de Pedro Ciruelo. Se presupone un equilibrio en la cualificación científica de ambos, uno es el autor del Commentum sobre la Esfera de Sacrobosco —el darocense-, mientras que el otro — el burguense- conoce bien el libro y no está de acuerdo con las innovaciones que ofrece su interlocutor.

Mientras en el tratado encontramos autorías perfectamente diferenciadas, las de Sacrobosco, Pedro de Ailly y Pedro Ciruelo, los personajes del diálogo son designados por el toponímico, no por sus nombres propios: se presentan como dos estudiantes extranjeros en Paris, uno de los cuales, el darocense, ${ }^{19}$

16. Para una visión de conjunto sobre el género en España: Andrés Renales, (1986), Ferreras (1985), (2003) y Gómez (1988) (2000).

17. Es de una extraordinaria calidad, se aproxima en su desarrollo retórico a una oratio y no desdice de las mejores piezas del humanismo coetáneo.

18. Para el prefacio y el diálogo, Cirilo Flórez Miguel, Pablo García Castillo y Roberto Albares Albares (1990, 55-193 y 37-53), (1998, 109-
112) y Roberto Albares (1996,177-204). Sobre el punto de vista argumentativo y dialógico es referencia fundamental Esther Gómez Sierra (1999, 83-104).

19. El darocense se presenta en el diálogo como el autor del tratado previo, pero ya lo indica también el título de la obra: Uberrimum Sphere mundi comme[n] tum / [Johannis de Sacro Busto anglici; una cum textualibus optimisq[ue] additionibus ac vberrimo commentario Petri Ciruelli darocensis ..., 
ha escrito unos comentarios en los que se realizan críticas y correcciones a la Esfera de Sacrobosco, postura que desata los reproches de su colega burguense (Gonzalo Gil). El diálogo se desarrolla en tres fases; ${ }^{20}$ en la primera se polemiza acerca de la función de la auctoritas, y se discute si es legítimo innovar los conocimientos de los antiguos que han sido respetados durante siglos. El burguense se encuentra con su amigo, que ha editado unos comentarios sobre la Esfera, y expone una objeción de fondo a su trabajo: «Y no te ha parecido bastante si no cambiabas también en los más de los lugares el texto del autor (al que y no sin razón veneraron muchos siglos antes de nosotros) y, por así decirlo, lo has innovado»; razona su crítica diciendo: "porque estimo que varón aprobado por tantos siglos no puede en modo alguno ser reprochado sin deshonor por nadie» (pág. 139).

El autor del libro, el darocense, aduce ejemplos varios de grandes autores (desde Aristóteles a Escoto, pasando por S. Pablo) que han corregido o confutado las ideas de sus predecesores y, como cierre, resume su idea acerca de la construcción de la ciencia:

Es efecto de alma libre, a los otros, si alguna vez se equivocaron como hombres, o interpretarlos con piedad o corregirlos y proteger siempre, según sus fuerzas, la verdad. Y porque los predecesores hayan sido muy entendidos, no por eso se ha de pensar que a los venideros les está cerrado el camino de hallar la verdad. En efecto, los acrecentamientos de las ciencias, como los ríos — testigo el filósofo—, se hacen por adición continua (pág. 147).

En esta primera parte se enfrentan dos concepciones de método científico, una - el burguense Gonzalo Gil— defiende que la función del comentarista es simplemente la de glosar o aclarar el significado de un texto, mientras que otra - el darocense Ciruelo - considera que para el progreso científico es necesario añadir, corregir o refutar. Por supuesto, triunfa este último punto de vista y el burguense admite que estaba equivocado.

En la segunda parte del diálogo, una vez alcanzado un acuerdo a propósito del método científico, la conversación se concentra en las opiniones innovadoras del tratado - del que, casualmente, llevaba el darocense un ejemplar-: «Pero, ea, lee ahora en voz alta los lugares singulares en los que te parece que o hemos añadido mal algo o que hemos cambiado el orden de la letra» (pág. 153). Así, de forma verosímil, se impone un orden al proceso conversacional; la discusión gira en torno al tratado que los personajes tienen delante y sigue su disposición; los interlocutores leen citas del propio texto y van comentando libro por libro las dudas que plantean las adiciones de Ciruelo a su amigo burguense. Esta parte del diálogo muestra la cualificación de ambos interlocutores en cosmografía y sirve para dos propósitos: por un lado justificar y ratificar

20. Esther Gómez Sierra (1999, 95-96) y Cirilo Flórez et al. (1990, 44-45). 
el acierto de las modificaciones introducidas en los comentarios de Ciruelo, por otro, aclarar y ampliar los razonamientos del tratado con las contestaciones a las preguntas de su interlocutor. El tratado también argumentaba las innovaciones, las aportaciones inéditas de Ciruelo a la cosmografía, pero el diálogo refuerza la importancia de estas aportaciones porque en él asistimos a la aquiescencia de un oponente cualificado y remiso; no es la presencia del disenso con la tradición lo que distingue al tratado del diálogo, sino el acuerdo del burguense con las tesis de Ciruelo, que se manifiesta de forma explícita en el coloquio.

Al final del diálogo se proporciona una clave adicional sobre su propósito; Ciruelo pide la aprobación de su amigo para la publicación del libro: «Por consiguiente ¡estás contento y te place lo bastante para que esto se edite?» (pág. 177). Aunque en las disputas parciales el burguense tiene que desdecirse y conceder la razón al autor del libro, esta pregunta desvela que hemos asistido a una especie de examen inverso en el que es el darocense quien necesita la aquiescencia de su amigo para la publicación de su obra. Se corrobora así el equilibrio en la cualificación de ambos interlocutores, y el diálogo, que se publica al final del tratado, se revela como un punto de partida para su publicación; en palabras de Esther Gómez Sierra: «Darocensis displays his teaching expertise with a twist, as he assumes at the beginning of the discussion the role of examinee or graduand, if only with the hidden intention of proving his point more effectively» $(1999,100)$. El texto se cierra con bromas entre estos estudiantes extranjeros en París, bromas que muestran la cercanía y el afecto mutuo.

Este diálogo no tiene un propósito divulgativo (está redactado en latín), exige idéntico grado de especialización que el tratado previo, con la diferencia de que la polémica se circunscribe a un aspecto del Commentum; el proceso argumentativo muestra a través de las sucesivas etapas el acuerdo del burguense, Gonzalo Gil, con las innovaciones introducidas por el darocense en la tradición cosmográfica previa. Por otra parte, el decoro, la necesidad de respetar el contexto ficcional con la caracterización de los interlocutores como estudiantes, añade también una dimensión festiva a la polémica que la aleja del tono del tratado, del que, sin embargo, depende directamente.

\section{Coloquio entre Montaña de Monserrate y el Marqués de Mondéjar}

El Libro de la Anothomia del hombre de Bernardino Montaña de Monserrate consta de un tratado, un sueño alegórico del marqués de Mondéjar y un "Coloquio del Ilustríssimo señor don Luys Hurtado de Mendoça, marqués de Mondéjar, con el doctor Bernardino Montańa de Monserrate, médico de su Magestad, acerca del dicho sueño que soñó su señoría de la generación, nascimiento y muerte del hombre»; cabe destacar que tratado de anatomía y diálogo tienen casi la misma longitud. En este caso el diálogo no surge directamente del tratado, 
sino del prolijo sueño del marqués de Mondéjar que da pie al coloquio entre el autor - Montaña de Monserrate- y el marqués. ${ }^{21}$

El diálogo comienza con un soliloquio del marqués, admirado de lo que había sońado esa noche; en ese momento aparece el doctor Montańa de Monserrate y el marqués aprovecha para relatarle por extenso el sueño. Se trata de una larga visión alegórica del cuerpo humano, ${ }^{22}$ representado como una fortaleza vivificada, que al comienzo aparece en proceso de construcción y al final se derrumba. El texto de este sueño va acompańado de anotaciones marginales con la interpretación del significado de cada uno de sus elementos.

La representación alegórica del cuerpo humano tiene una función de engarce o bisagra entre las dos partes del libro. Por una parte sirve de recurso mnemotécnico, como advierten las piezas preliminares: «narra esta materia [anatomía] muy compendiosamente por una figura muy graciosa, la cual es de muy gran fruto para tener en la memoria todo lo más que en este libro se contiene, por esa causa acordé de ponelle en fin de esta obra» (fol. 1v); por otra parte, el sueño añade una dimensión dinámica a la exposición del tratado anatómico, puesto que en él se representa alegóricamente la «generación, nascimiento y muerte del hombre» (fol. 4v).

El sueño también sirve como elemento estructurador del posterior diálogo, en el que la sucesión de asuntos va marcada por el relato de la representación alegórica del cuerpo humano; es procedimiento similar al utilizado por Pedro Ciruelo para imponer de manera verosímil un orden al desorden característico de la conversación.

El coloquio entre los interlocutores remite al sueño y también al tratado de anatomía de Montaña de Monserrate en muchas ocasiones: unas veces lo hace para justificar y apoyar preguntas o respuestas («Según lo que avemos dicho en

21. Todas las citas por la editio princeps, Valladolid, Sebastián Martínez, 1551. Puede consultarse en: http://alfama.sim.ucm.es/dioscorides/consulta_libro.asp? ref=X530015187\&idioma $=0$. (Catálogo Digital de la Universidad Complutense) El diálogo ha sido estudiado por Jacqueline Ferreras (1993, 95-102) y (2006, 177-201); para el estudio médico del texto, vid. Barona (1993, 47-76)

22. El empleo de la alegoría para la explicación científica es relativamente común y cuestiona de raíz la pretendida asepsia de la literatura científica; en el siglo xv, la Visión deleitable de filosofía de Alfonso de la Torre narra el viaje alegórico del Entendimiento en busca de la Verdad; la obra es un compendio de filosofía aristotélica de gran éxito y repercusión poste- rior. La descripción alegórica del cuerpo viene recogida ya en los títulos de algunos de los textos de anatomía más prestigiosos del momento, como el De humani corporis fabrica libri septem de Vesalio (1542) y L'edificio del corpo humano di M. Francesco Sansovino (1550); en España, Lobera de Ávila, médico de Carlos V, también había incluido un sueño alegórico en un tratadito anatómico; vid. Luis Alberti López (1948). En otros ámbitos, el Somnium de Kepler utiliza materiales de ficción procedentes de Luciano para proporcionar una nueva visión científica; recientemente, Jauch (1985, 75-81) incluye el sueño de uno de los interlocutores (con reminiscencias borgianas) en un diálogo sobre mecánica cuántica inspirado en el Dialogo de Galileo. 
nuestra anothomía», fol. 99r), otras, en cambio, para evitar repeticiones sobre asuntos desarrollados en el tratado previo: «me acuerdo de lo que havéys dicho en vuestra anothomía del pecho, pero una cosa no declarastes en ella que deseo saber» (fol. 98v). Las referencias del Marqués demuestran su familiaridad con el tratado de anatomía.

En este libro los personajes difieren en su grado de cualificación; Montaña es un profesional reputado que responde las dudas y preguntas; el marqués desempeña la función de discípulo ilustrado en la materia - por ejemplo, conoce bien el tratado de anatomía de Monserrate, cita con familiaridad a Aristóteles, Galeno o Avicena (el príncipe Abenali)—, un discípulo poco acomodaticio, hábil en la búsqueda de contradicciones y que en algún momento pone en aprietos a su interlocutor obligándole incluso a reconocer las limitaciones de la ciencia: «muchas vezes nos contentamos de saber por experiencia la verdad de algunas cosas aunque no alcancemos la causa dellas» (fol. 124v).

El marqués conduce y hace avanzar el diálogo con preguntas directas, objeciones, dudas, puntualizaciones y órdenes: «algunas dudas se me acrescen ... mas quédense por ahora» (fol. 86v); «vamos adelante ...» (fol. $81 \mathrm{r}$, y cada vez que se cambia de asunto); «volvamos al lugar de donde nos divertimos a hablar en aquella materia» (fol. 89r), etc.

Pero a pesar de la estrecha relación entre diálogo, sueño y tratado, marcada por todas estas alusiones, la conversación entre Montaña de Monserrate y el marqués de Mondéjar no es un comentario sobre el libro de anatomía ni se limita a ofrecer la interpretación del sueńo, que, por otra parte, ya se explicaba en las notas marginales. En el diálogo se desarrollan asuntos que no aparecían en el tratado, aunque se apoye en él. Mientras que en el libro de anatomía prevalece un discurso asertivo, limitado a la descripción de las partes del cuerpo como corresponde a esta especialidad médica, en el diálogo la atención de los interlocutores se centra en lo que actualmente estudia la fisiología, en el funcionamiento de los miembros del cuerpo. El marqués de Mondéjar verbaliza este cambio: «Dexemos esto que toca a la anothomía y fábrica del coraçón y bolvamos a hablar en sus obras» (fol. 95v). ${ }^{23}$

En esta ocasión, a diferencia de lo que sucedía en la obra de Ciruelo, el diálogo no pretende ratificar o profundizar en el libro previo, sino que desarrolla asuntos nuevos con una perspectiva complementaria del cuerpo humano. Destaca, por ejemplo, que se plantee en él la relación cuerpo-alma; es posible que con el debate sobre una cuestión asi se pretenda subsanar el materialismo inherente de la descripción anatómica, en la que sólo tiene cabida la observación física.

23. Jacqueline Ferreras señala esta diferencia entre la materia de ambos textos y, al mismo tiempo, defiende que el diálogo es una recapi- tulación del Libro de Anatomía, afirmación de la que disiento: el «Sueño» sí funciona como recurso mnemotécnico, pero no el diálogo. 
La cuestión es, ¿por qué elegir un género distinto para cada caso? Una de las razones se adelanta en las piezas preliminares, en las cuales el autor indica a qué tipo de lectores se dirige, justifica la importancia de la materia, deja clara su capacitación intelectual y se refiere a la existencia de polémicas profesionales acerca del ejercicio de la medicina en las que se muestra muy beligerante.

Montaña de Monserrate reprueba el trabajo de autores previos que:

han tratado esta doctrina [la anatomía] hasta agora del tal manera, que sin embargo que escriven todo lo necesario que sepa el médico pero a bueltas de aquello tratan de algunos primores y secretos de naturaleza, los quales no solamente no son necessarios al médico, pero son muy grande estorvo para su propósito, porque estudiando en ellas dexan de estudiar en otras cosas que son muy necessarias (fol. 1v).

\section{Crítica que reitera poco después:}

pero, en fin, la mayor parte de aquellas delicadezas y secretos y obras maravillosas de la naturaleza son para el médico y el cirujano inútiles y no sirven nada para su fin, ... antes estudiar en ellas les estorvaría de estudiar y entender otras cosas que les son necessarias (fol. $3 r)^{24}$.

La obra plantea así la necesidad de una mayor especialización profesional de los médicos, al advertir que muchas cuestiones relativas a la filosofía natural son innecesarias para el ejercicio de la medicina. Este es el motivo de la división de dos partes y de la utilización de dos géneros literarios; el tratado contiene «todo lo que es necesario acerca de la compostura del cuerpo humano para el fin y el propósito del médico», mientras que el diálogo es «una declaración en la cual se trata a vuelta de otras cosas algunas materias que, puesto que para los médicos no son necesarias, pero son apazibles a algunos curiosos y amigos del saber» (fol. 1v).

La división del texto en dos partes permite poner en práctica este enfoque sobre la profesión de la medicina: en la primera, dirigida a médicos y cirujanos, se atiene escrupulosamente a la descripción material del cuerpo de forma concisa y clara. En cambio, el diálogo trata de ciertos 'secretos de naturaleza' que tanto interesan a los médicos, pero que, a juicio de Montańa de Monserrate, son ajenos a la profesión, más propios de gente curiosa y discreta. Sobre estas cuestiones naturales cabe el disenso, pues se ofrecen puntos de vista alternativos a los del autor y se demuestra que estos asuntos laterales son superfluos para el desempeño profesional desde el momento en que se debaten con un simple afi-

24. La defensa del empleo de la lengua vernacular se asocia también a la necesidad de una mayor especialización profesional: «porque hallo que en este tiempo los médicos están tan aficionados al latín que todo su pensamiento emplean en la lengua, y lo que haze más al caso, que es la doctrina, no tienen más pensamiento dello que si no la leyessen («Epístola», fol. a2r). 
cionado. ${ }^{25}$ Como resultado adicional se refuerza el efecto de que lo desarrollado en el tratado es incontrovertible y categórico, sin opción para el desacuerdo.

El empleo de los dos géneros (más el sueño alegórico) sirve también a Montańa de Monserrate para ampliar el número de lectores potenciales: se dirige a médicos especialistas y además a personas curiosas y amigas del saber como su interlocutor, que es un simple aficionado, pero no un personaje cualquiera. En la figura del marqués, que representaría a los nobles de la corte, el autor está halagando y atrayendo a la clientela más importante para su profesión. El éxito profesional y económico de los médicos dependía directamente de la categoría social de sus pacientes, e incluso una parte de la literatura médica en lengua vulgar de la época está destinada específicamente a este grupo social (el Libro de las cuatro enfermedades cortesanas de Lobera de Ávila, publicado en 1544, es el más explícito al respecto).

En este libro el empleo del diálogo sí está asociado al propósito de divulgación de conocimientos generales y accesorios sobre materia, aunque sus funciones son bastante complejas y no se limitan a este objetivo. Pero la divulgación no es inmanente al diálogo como género, sino que está relacionada con la caracterización de los interlocutores - experto y aficionado, maestro y discípuloque necesariamente condiciona el proceso argumentativo; el diferente grado de especialización en la materia configura el carácter divulgativo del diálogo.

\section{Diálogos de Aritmética}

El caso de los Diálogos de Aritmética de Pérez de Moya es muy distinto y, en cierto modo, paradójico. Pérez de Moya es autor de un gran número de libros, casi todos en lengua vulgar, y sobre materias dispares: tratados de aritmética para la enseñanza o el aprendizaje en niveles muy distintos (desde un manual de contadores a un libro sobre álgebra), una extensa obra sobre filosofía natural, un compendio de símiles sobre vicios y virtudes para predicadores, un libro de mujeres santas e ilustres, un tratado de mitología; en todos ellos utiliza una estructura de tratado o de manual, aunque no traten de materias científicas. ${ }^{26}$ Los Diálogos de Aritmética no llegaron a publicarse de forma independiente. Aparecen como un libro introductorio de la primera obra de Pérez de Moya, el

25. La idea de que el diálogo es más adecuado para desarrollar asuntos laterales a la disciplina principal aparece también en el prólogo del Tratado de las cosas medicinales; Acosta justifica la elección del tratado en vez del diálogo (como había hecho García Horta), porque «así como su obra trata de diversas medicinas y plantas y otras cosas pertenecientes a la salud humana, así también trata de otras que son inútiles y sin algún provecho para ella, siéndole forzoso tratarlas por seguir el estilo de diálogos, do los que hablan suelen divertirse, y derramarse fuera de lo que toca a su principal propósito» (Cuartero 1993, 91)

26. Vid. Aurelio Valladares Reguero (1997, 371-412), Pérez de Moya (1987) y para la edición (1998, XXII-XXV y 557-618); las citas remiten a esta edición. 
Libro de cuenta, que trata de las quatro reglas generales de Arithmética ... (Toledo, Juan Ferrer, 1554), un manual de nivel elemental, y luego serán el libro nono y último de la Aritmética práctica y especulativa (Salamanca, Mathias Gast, 1562), un extenso compendio que incluye las novedades aritméticas del momento. El hecho de servir tanto de apertura como de cierre de dos obras distintas pone de relieve su independencia respecto al tratado al que acompaña. ${ }^{27}$

El diálogo se desarrolla en dos partes precedidas del correspondiente resumen del contenido. En la primera Antímaco — un estudiante de leyes — visita a Sofronio, personaje de más edad que está convaleciente, y lo encuentra leyendo un libro de aritmética; la conversación se desenvuelve en torno a la dignidad de esta disciplina, su importancia en el conjunto de las ciencias e incluso para la vida cotidiana. Comienza de forma provocadora, cuando Antímaco pregunta: "¿qué gusto o qué fruto halláys en esta arithmética que tanto os ocupáys en ella? [...] Por dicha pretendéys assentar por criado de tienda de algún ginovés rico?» (pág. 560). La respuesta marca el tono de la subsiguiente defensa de la aritmética: «No, en verdad, que soy muy harón para servir, pero las sciencias no se han de deprender por el interesse que dellas se espera, sino por la perfectión que traen al hombre» (pág. 560). Resulta contradictorio - pero también ilustrativo sobre el estatuto de las ciencias y el trabajo en el Renacimiento español- que para dotar de dignidad científica a la aritmética se la despoje de utilidad profesional, de interés económico.

Es un diálogo con dos puntos de vista encontrados en el que Sofronio desempeña la función de maestro de un discípulo socarrón y renuente, para lo cual comienza por alabar la aritmética como la más necesaria y excelente de todas las artes liberales. Antímaco rebate esta primera intervención; discrepa de que sea un arte liberal y de la necesidad de su estudio. Para llevarle a su terreno Sofronio cambia los términos de la disputa: pasa a hacerle preguntas concretas y a exponerle anécdotas que muestran la importancia de tener ciertas nociones aritméticas para desenvolverse en la vida diaria; las anécdotas se presentan como casos reales, aunque algunas son conocidos juegos matemáticos. Con este procedimiento el maestro pone en evidencia la ignorancia de su interlocutor y en el último ejemplo demuestra la necesidad del conocimiento de las matemáticas incluso para que un jurista - como Antímaco- pueda emitir una sentencia justa.

Los argumentos en defensa de la aritmética son aparentemente contradictorios: Sofronio afirma que el objeto fundamental de su estudio es la perfección del hombre, pero los ejemplos concretos utilizados para su defensa inciden solamente en su utilidad práctica para defenderse de los engaños ajenos; ello indica que en el diálogo subyace el concepto tradicional de artes liberales que, como

27. No es indiferente el lugar que ocupa. Aparece abriendo un libro de aritmética elemental, como acicate para su estudio; se utiliza como cierre distendido de un tratado destinado a lectores de un nivel académico mucho más elevado. 
propias del hombre noble o libre, están reñidas con el desempeño de una actividad remunerada («soy muy harón para servir»). ${ }^{28}$

Al final Antímaco reconoce que estaba en un error y que «si hasta aquí he negado más ha sido por disputar que por pensar ser verdad lo que yo dezía, principalmente que he leýdo tener todas las demás disciplinas necessidad desta arte, y ella no de otra ninguna». Concluye pidiéndole que le comunique «algunos cuentos o secretos que dizen de arithmética» (pág. 574).

En la segunda parte del diálogo se incorporan a la conversación dos nuevos estudiantes aficionados a las matemáticas —Damón y Lucilio—; cambian el propósito y el tono del diálogo, mucho más jocoso y distendido. Una vez admitida la dignidad de la aritmética, asistimos a una reunión propia de estudiantes en la cual - y a instancias de Sofronio, que sigue desempeñando la función de maestroplantean problemas y juegos matemáticos. Como advierte la introducción «se prosigue la plática entre todos cuatro, diciendo cada uno las preguntas o dislates que sabe, así como se haze cuando en las noches de Navidad se junta algún número de gente alrededor del fuego, todo por términos comunes de aritmética» (pág. 575). Los juegos no requieren conocimientos aritméticos profundos y gozaron de gran éxito entre los especialistas debido a su ingenio, a su carácter sorprendente. Todos ellos están documentados en la tradición previa, aunque, como suele hacer Pérez de Moya, no se indique.

Llama la atención que, al ser utilizados para entretener el ocio del convaleciente y sus interlocutores, los conocimientos de aritmética pasen a desempeñar la misma función que las anécdotas, facecias y cuentecillos y se pongan al servicio de la vida social como forma de recreación; sirven para entretener, amenizar y sorprender en las reuniones distendidas entre amigos, pasando por alto su utilidad profesional, en la línea de lo que sucede en la conversación de la primera parte del texto.

A diferencia de los textos anteriores, en éste el diálogo no está adosado al tratado, sino que forma parte del manual de aritmética porque es uno de los libros que lo integran y, al mismo tiempo se mantiene independiente de él: carece de la más mínima alusión al resto de la obra y sus interlocutores son puros entes de ficción. Tampoco aparece aquí la figura del autor como interlocutor, los personajes son estudiantes cuyos rasgos proceden de la tradición literaria: abunda el humor, tienen poco dinero y mucha hambre, hacen bromas sobre la necesidad de empeñar los manuales y, cómo no, aluden al cómico Terencio y conocen bien el texto de La Celestina. ${ }^{29}$

28. Nótese que el interés por la ciencia no va acompañado necesariamente de una perspectiva social innovadora; aunque la labor de compilación y divulgación de Pérez de Moya incluyó novedades matemáticas apreciables, el diálogo revela una total ausencia de aprecio del trabajo, ofrece un enfoque propio de una socie- dad estamental e inmovilista.

29. Este diálogo es la única obra de ficción de la extensísima producción de Pérez de Moya; el cuidado en la caracterización individualizada de los personajes, en la creación del ambiente y las alusiones literarias tienen especial significado por tratarse de un autor que prodiga críticas 
¿Qué sentido tiene este diálogo en el Libro de Aritmética? Las razones de su presencia se explican porque la obra está concebida como una summa, un compendio de partes diversas de la aritmética pensado para niveles de formación muy amplios - desde niños que aprenden las cuatro reglas y contadores a especialistas muy cualificados-, con la particularidad de que estas partes no mantienen un orden progresivo de dificultad, son independientes entre si ${ }^{30}$ (por ejemplo, el libro 6 enseña a contar sin pluma y a convertir monedas mediante reglas mnemotécnicas). La aritmética recreativa, los juegos matemáticos son otra parte de la materia que contaba con una larga tradición. En vez de limitarse a describir estos juegos, Pérez de Moya aprovecha las posibilidades del diálogo para mostrarlos en el contexto más apropiado, las circunstancias de ocio de la vida social en las que este tipo de saber es también útil: una reunión entre amigos.

\section{Conclusiones}

A la vista de estas obras, parece que los autores de textos científicos en el Renacimiento no perciben el diálogo y el tratado como géneros en competencia, como simples alternativas que eligen en función del grado de rigor científico, de especialización de sus obras o de divulgación. La disyuntiva entre uno y otro género se resuelve en función de variables mucho más complicadas. Los tres textos presentan grandes diferencias en el grado de especialización científica del diálogo, en el grupo de receptores a quien están dirigidos y en los objetivos que pretenden. Tales diferencias se apoyan, fundamentalmente, en la caracterización de los personajes y el grado de equilibrio en sus conocimientos; el mayor o menor carácter polémico o divulgativo de los textos está relacionado con el diseño de los interlocutores, más que con la elección del género.

Ciruelo, mediante dos interlocutores igualmente cualificados, utiliza el diálogo para justificar y apoyar las innovaciones que introduce en el tratado de Cosmografía de Sacrobosco. Montaña de Monserrate, en cambio, incluye a un interlocutor aficionado - de reconocido prestigio social - y no profesional de la medicina para ampliar el ámbito de los receptores potenciales. Pérez de Moya diseña unos estudiantes dicharacheros, simples aficionados a la aritmética (y más a algunos juegos, como los dados), para mostrar en directo las posibilidades que ofrece el conocimiento de la aritmética en la vida social.

Los tres textos, con la cooperación entre ambos géneros, permiten observar también cómo se aprovecha el diálogo para reforzar las tesis polémicas defendi-

contundentes a la literatura de ficción, en la línea de un Alejo de Venegas. Para esta hostilidad hacia la ficción vid. C. Baranda (2000).

30. 1) las cuatro reglas; 2) quebrados; 3) regla de tres $[\ldots]$ y cosas tocantes al arte menor; 4) geometría práctica; 5) aritmética especulativa; 6) reglas para contar sin pluma y reducir monedas; 7) compendio de la regla de la cosa [álgebra]; 8) caracteres, monedas y pesos antiguos; 9) diálogo. 
das en los tratados porque en ellos podemos comprobar como si se tratara de un caso práctico, a través de la ficción, lo acertado de dichas tesis. Ciruelo ofrece el asentimiento de un especialista en cosmografía inicialmente reacio a admitir las nuevas aportaciones del autor que, a través del diálogo, va manifestando sus acuerdos sucesivos con las innovaciones y, al final, da el visto bueno para su publicación. Montańa de Monserrate presenta a un interlocutor aficionado a la medicina, pero culto, capaz de participar en un debate sobre las materias que el autor había defendido que no son propias de especialistas; el diálogo es la forma empírica de apoyar su posición. Por último Pérez de Moya consigue que asistamos a una reunión de estudiantes bromistas que se entretienen con juegos matemáticos, mostrando así la diversidad de aplicaciones de la aritmética, su utilidad en todos los ámbitos de la vida, incluso para los momentos de recreación. 


\section{Bibliografía citada}

Albares Albares, Roberto, «El humanismo científico de Pedro Ciruelo» en La Universidad complutense cisneriana: impulso filosófico, científico y literario, coord. Luis Jiménez Moreno, Madrid, Editorial Complutense, 1996, págs. 177-204.

Alberti López, Luis, La anatomía y los anatomistas españoles del Renacimiento, Madrid, CSIC, 1948.

Alonso de Herrera, Gabriel, Libro de agricultura, ed. José Urbano Martínez Carreras, Madrid, Atlas, 1950, B.A.E., 235.

Altieri-Biagi, Ma Luisa, "Forme della comunicazione scientifica», en Letteratura italiana, dir. A. Asor Rosa, vol. III, Torino, Einaudi, 1984, págs. 891-947 y en Fra lingua scientifica e lingua letteraria, Istituti Editoriali e Poligrafici Internazionali, Roma, 1998, págs. 21-73.

Andrés Renales, Gabriel. Diálogos literarios del siglo XVI. Memoria de licenciatura. Madrid. UCM, Facultad de Filología, Depto. Literatura Española. 1986.

Arfe y Villafañe, Juan de, De varia commensuración para la esculptura y architectura, int. Antonio Bonet Correa, Madrid, Ministerio de Educación y Ciencia, 1974.

Baranda, Consolación, «La mitología como pretexto. La Filosofía secreta de Pérez de Moya", Homenaje a Francisco Ynduráin, Principe de Viana. Anexo 18, 2000, págs. 49-65.

Baranda, Consolación, «Los lectores del Dioscórides, estrategias literarias del doctor Laguna», Criticón, 58 (1993), págs. 17-24.

Baranda, Consolación, «Objetividad y primera persona: el yo en los tratados científicos del Renacimiento", Compás de Letras 1 (1992), págs. 75-89.

Barona, Josep Lluís, «Bernardino Montańa de Monserrate: el galenismo y la tradición alquímica", en Sobre medicina y filosofía natural en el Renacimiento, Valencia, Seminari d'estudis sobre la ciència, 1993, págs. 47-76.

Cuartero Sancho, Pilar, «Los autores grecolatinos de literatura científica, modelos literarios de la literatura científica en castellano del Siglo de Oro", Criticón 58 (1993), págs. 85-93.

Ferreras, Jacqueline, «Didactismo y arte literario en el diálogo humanístico del siglo Xvı», Criticón 58 (1993), págs. 95-102.

Ferreras, Jacqueline, «Du traité au dialogue: les enjeux linguistico-philosophiques de l'humanisme» en Les dialogues ou les enjeux d'un choix d'écriture (pays de langue romane), ed. Philippe Guérin, Rennes, Presses Universitaires, 2006, págs. 177-201.

Ferreras, Jacqueline, Les dialogues espagnoles du XVIe. siècle ou l'expression littéraire d'une nouvelle conscience, Lille, Université de Lille. 1985 (2 vols.).

Ferreras, Jacqueline, Los diálogos humanisticos del siglo XVI en lengua castellana. Murcia, Universidad de Murcia, 2003. 
Flórez Miguel, Cirilo, García Castillo, Pablo y Albares Albares, Roberto, Pedro Ciruelo. Una enciclopedia humanista del saber, Salamanca, Caja de Ahorros, 1990, págs. 55-193

Flórez Miguel, Cirilo, García Castillo, Pablo y Albares Albares, Roberto, El humanismo científico, Salamanca, Caja de Ahorros, 1988, págs. 109-112.

Gómez, Jesús, El diálogo en el Renacimiento español, Madrid, Cátedra, 1988.

Gómez, Jesús, El diálogo renacentista, Madrid, ed. Laberinto, 2000.

Gómez Sierra, Esther, «Home and away in Paris: Pedro Sánchez Ciruelo and his Disputatorius dyalogus», en Latin and Vernacular in Renaissance Spain, ed. Barry Taylor and Alejandro Coroleu, Manchester, Manchester Spanish and Portuguese Studies, Cañada Blanch Centre for Advanced Hispanic Studies, 1999, págs. 83-104.

GutiÉrrez Rodilla, Bertha M., «La medicina, sus textos y sus lenguas en la España de Cervantes», http://medtrad.org/panacea/IndiceGeneral/n_21-22_ tribuna_GRodilla.pdf

Jauch, J. M., Sobre la realidad de los cuantos, Madrid, Alianza, 1985.

Locke, David, La ciencia como escritura, Madrid, Cátedra, 1997 (Yale University, 1992).

Mancho Duque, Ma Jesús, «Los prólogos de la literatura científica en el Renacimiento: la cuestión de la lengua» en Memoria de la palabra. Actas del VI Congreso de la Asociación Internacional Siglo de Oro, Burgos-La Rioja, 15-19 julio 2002, coord. Ma L. Lobato López y F. Domínguez Matito, vol. II, 2004 págs. 1229-1243.

Mancho, Ma Jesús, «La lengua española, vehículo de divulgación científica en el Renacimiento" en Pórtico a la ciencia y la técnica del Renacimiento, ed. Ma J. Mancho, Salamanca, Junta de Castilla y León-Universidad de Salamanca, 2001, págs. 45-84.

Montaña de Monserrate, Bernardino, Libro de la Anothomia del hombre, Valladolid, Sebastián Martínez, 1551.

Pérez de Moya, Juan, Arithmética práctica y speculativa. Varia historia de sanctas e illustres mugeres, ed. Consolación Baranda, Madrid, Biblioteca Castro, 1998.

Pérez de Moya, Juan, Diálogos de artimética práctica y especulativa, ed. de R. Rodríguez Vidal, Zaragoza, Universidad, 1987.

Valladares Reguero, Aurelio, «El bachiller Juan Pérez de Moya. Apuntes biobibliográficos», Boletín del Instituto de Estudios Giennenses, CXLV (1997) págs. 371-412.

Venegas, Alejo de, «Prólogo» a Cervantes de Salazar, Francisco, Apólogo de la ociosidad y el trabajo, ed. Consolación Baranda, Salamanca, Universidad, (en prensa).

Vian Herrero, Ana, «Algunas técnicas literarias de Andrés Laguna en la descripción de simples: Las «Anotaciones» a Dioscórides y la tradición literaria greco-bizantina", en Andrés Laguna: humanismo, ciencia y política en la Eu- 
ropa renacentista. Congreso Internacional Segovia 22-26 de noviembre, 1999, coord. J.L García Hourcade y J.M Moreno Yuste, Castilla y León, Consejería de Educación y Cultura, págs. 205-238.

Vian Herrero, Ana, «Interlocución y estructura de la argumentación en el diálogo: algunos caminos para la poética del género", Criticón 81-82 (2001), págs. 157-190.

Vian Herrero, Ana, «La ficción conversacional en el diálogo renacentista», Edad de Oro 7 (1988), págs. 173-188.

YNDURÁIN, Domingo, "La invención de una lengua clásica (Literatura vulgar y Renacimiento en España», Edad de Oro I (1982), págs. 13-34, citado por Estudios sobre Renacimiento y Barroco, ed. C. Baranda, Ma L. Cerrón, I. Fernández-Ordóńez, J. Gómez y A. Vian, Madrid, Cátedra, 2006, págs. 81-105.

Yndurárn, Domingo, "Los diálogos en prosa romance», en Homenaje a Francisco Ynduráin, Anejos de la Fundación Príncipe de Viana, 18 (2000), págs. 435-466; citado por Estudios sobre Renacimiento y Barroco, págs. 333-376. 